\title{
Infecciones por virus respiratorios en niños con leucemia linfoblástica aguda y neutropenia febril: Estudio prospectivo
}

\author{
Marlis Täger F., Paola Zolezzi R., Isabel Folatre B., Maritza Navarrete C. y Juana Rojas P.
}

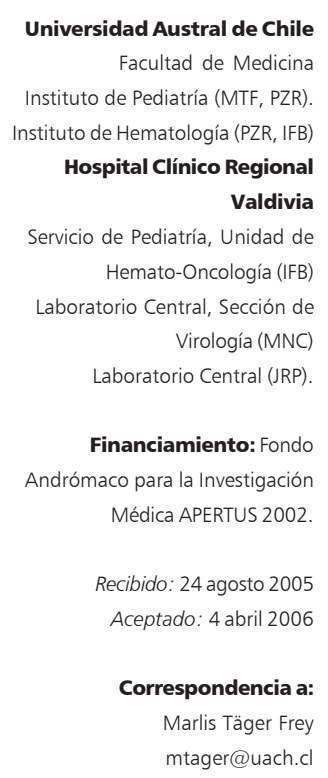

\section{Respiratory virus infections in children with acute lymphoblastic leukemia and febrile neutropenia: A prospective study}

Respiratory viruses are the most common infections in healthy children. The impact of these infections in cancer patients has been only recently recognized in Chile. Aim: To establish the frequency and epidemiologicalclinical profile of respiratory virus infections in children younger than 15 years of age-with-acute lymphoblastic leukemia requiring hospitalization due to a febrile neutropenic episode. Methods: All children $<15$ years of age requiring hospitalization in the Regional Hospital of Valdivia, Chile, with cancer, fever and neutropenia between November 12002 and October 312004 were studied. Nasopharygeal aspirate were obtained and tested by direct immunofluorescent assays for influenza A-B virus, parainfluenza virus type 1, 2, 3, respiratory syncytial virus (RSV) and adenovirus. Results: Respiratory viruses were detected in $25 \%$ of 44 febrile neutropenia episodes occurring in 25 patients. Viruses detected were, influenza (3/11), parainfluenza (3/11) RSV (2/11), adenovirus (1/11), parainfluenza + RSV (1/11), and parainfluenza + adenovirus (1/11). Four (36\%) of cases were nosocomial. Respiratory symptoms were present in 9 children, seven of whom had inferior respiratory tract symptoms. One patient died of persistent RSV infection, agranulocytosis and extensive bilateral pneumonia. Conclusions: Respiratory viruses were detected in $25 \%$ of febrile neutropenic episodes in children with ALL. This high detection rate together with the frequent involvement of the lower respiratory tract and the possibility of death strongly favors the inclusion of respiratory virus diagnostic tests in the evaluation of these children during autumn and winter season.

Key words: respiratory virus, febrile neutropenia, acute lymphoblastic leukemia.

Palabras claves: virus respiratorios, neutropenia febril, leucemia linfoblástica aguda.

\section{Introducción}

$\mathrm{L}$ as infecciones son una de las principales causas de muerte en pacientes inmunocomprometidos $^{1}$. Tradicionalmente se considera que tanto bacterias como hongos constituyen las etiologías infecciosas más comunes de las enfermedades respiratorias bajas en este grupo de pacientes. Sin embargo, en los últimos años los avances en las técnicas de diagnóstico viral han permitido reconocer a los virus respiratorios como agentes etiológicos significativos de patologías respiratorias agudas, causando importante morbimortalidad ${ }^{2}$. En hospederos inmunocomprometidos estas infecciones tienen mayor duración y gravedad. A diferencia de lo que ocurre en la población sana, se observa una mayor tendencia a comprometer el aparato respiratorio inferior derivando en traqueobronquitis, bronquiolitis o neumonías de rápida evolución, con complicaciones pulmonares graves y potencialmente letales, a veces no precedidas por sintomatología respiratoria alta ${ }^{2,3}$.

Estudios extranjeros describen altas frecuencias de infección viral en pacientes con neoplasias hematológicas y síntomas respiratorios: $37 \%$ en niños ${ }^{4}$ y 18 a $48 \%$ en adultos ${ }^{3-4,5}$. En nuestra institución, el aparato respiratorio constituye la localización más frecuente de infección en niños con $\mathrm{NF}^{6}$. En un estudio preliminar, retrospectivo, que abarcó un periodo de 2 años 5 meses, comprobamos la participación de virus respiratorios en $30,4 \%$ de 23 episodios de NF en 17 pacientes pediátricos portadores de LLA, que tenían sintomatología respiratoria y/o contacto epidemiológico con un caso índice?

Nuestro objetivo fue establecer la frecuencia y el perfil epidemiológico-clínico de las infecciones por virus respiratorios en pacientes pediátricos hospitalizados con el diagnóstico de LLA y un episodio de NF, con síntomas respiratorios o asintomáticos. 


\section{Pacientes y Método}

Estudio descriptivo y prospectivo, realizado entre el $1^{\circ}$ de noviembre del 2002 y el 31 de octubre del 2004 en pacientes bajo 15 años de edad, con diagnóstico de LLA y NF, que estaban internados en la unidad de Hemato-Oncología, Servicio de Pediatría, HCRV. En todos los pacientes se efectuó estudio de virus respiratorios, durante las primeras 48 a 72 horas de iniciado el episodio febril. Se registraron datos demográficos, epidemiológicos, clínicos y de laboratorio, evolución y terapia antimicrobiana. El examen se repitió al $7^{\circ}$ día en los pacientes con resultado positivo. Se excluyeron aquellos pacientes que tenían trombocitopenia grave con sangramiento activo.

Técnica de detección viral: Se obtuvo una muestra de secreción nasofaríngea con tubo nasogástrico introducido a través de las narinas, y se depositó en tubos colectores con PBS enviándose de inmediato, en frío, al laboratorio. La presencia de antígenos virales en células del aparato respiratorio superior fue detectada mediante IFD, utilizando anticuerpos monoclonales marcados con fluoresceína para 7 virus respiratorios: FLU A y B, parainfluenza 1, 2 y 3, VRS y ADV (kit para tamizaje e identificación de virus respiratorios: Bartels, Trinity Biotech Company, USA). Las muestras fueron analizadas en duplicado con controles $(+) \mathrm{s}$ y (-)s provistos por el fabricante. La lectura se realizó con microscopio de epi-iluminación Nikon, con lámpara de halógeno. Se consideró como muestra positiva la presencia de fluorescencia verde manzana intensa intracelular en dos o más células, con patrón de distribución característica según lo descrito en la literatura ${ }^{8}$.

Análisis estadístico: La significación estadística de la diferencia de proporciones se determinó mediante el test z. Para las otras variables se utilizó el test de Fischer, empleando el programa computacional Epi info 2004.

\section{Definiciones:}

Neutropenia febril: recuento absoluto de neutrófilos (RAN) menor de $1.500 / \mathrm{mm}^{3}$ y temperatura axilar $>38,5{ }^{\circ} \mathrm{C}$ en un control o $>38{ }^{\circ} \mathrm{C}$ en dos controles sucesivos, con un intervalo de al menos 4 horas. Neutropenia severa: RAN $\leq$ a $500 / \mathrm{mm}^{3}{ }^{6}$.

Se catalogó como infección intrahospitalaria (IIH) la presentación de sintomatología respiratoria y/o fiebre después del tercer día de internación.

Las infecciones del aparato respiratorio se clasificaron en superiores: compromiso nasal, faríngeo, ótico, sinusal, laríngeo, e inferiores: traqueobronquitis, bronquitis, síndrome bronquial obstructivo, neumonía intersticial, neumonía.

Proyecto aprobado por el Comité de Ética del HCRV.
Se obtuvo consentimiento informado de los padres y/ o tutor legal previo a su ejecución.

\section{Resultados}

Durante el periodo de estudio se produjeron 47 episodios de NF en 28 pacientes. Se excluyeron 3 pacientes, correspondientes a 3 episodios de NF: uno por presentar epistaxis masiva, otro por haber sido trasladado al HCRV al $7^{\circ}$ día de evolución de NF y un tercero, por omisión.

Se analizaron 44 episodios de NF en 25 pacientes: 13 de sexo masculino, edad promedio 6 años 8 meses (rango 1 año 7 meses - 14 años 7 meses). En 25\% de los episodios se detectaron virus respiratorios (11/44), correspondientes a 11 pacientes, (Figura 1). De ellos $36 \%$ (4/11) tenía antecedentes epidemiológicos de contacto con virus respiratorios. Treinta y seis por ciento adquirió la infección viral durante su hospitalización, que duró en promedio 20,7 días (rango 14 - 32).

La neutropenia duró en promedio 18,8 días (rango 7 a 37) y la fiebre 5 días (rango 1-14). Diez de los 11 pacientes con virus respiratorios $(91 \%)$ presentaron sintomatología respiratoria, en el paciente asintomático se comprobó infección por ADV. La IFD de control a los 7 días permaneció positiva sólo en un paciente con infección por VRS. Las características clínicas y de laboratorio se analizan en las Tablas 1 y 2. Los cultivos bacteriológicos de sangre, orina y deposiciones fueron negativos. Todos los pacientes recibieron tratamiento antimicrobiano según guías locales de manejo de $\mathrm{NF}^{6}$. Los tres pacientes con infección por virus FLU A recibieron además amantadina $(5 \mathrm{mg} / \mathrm{kg} /$ día vía oral, por 5 días). La evolución fue favorable en 10 pacientes (91\%). Falleció un escolar de 9 años, sexo masculino,

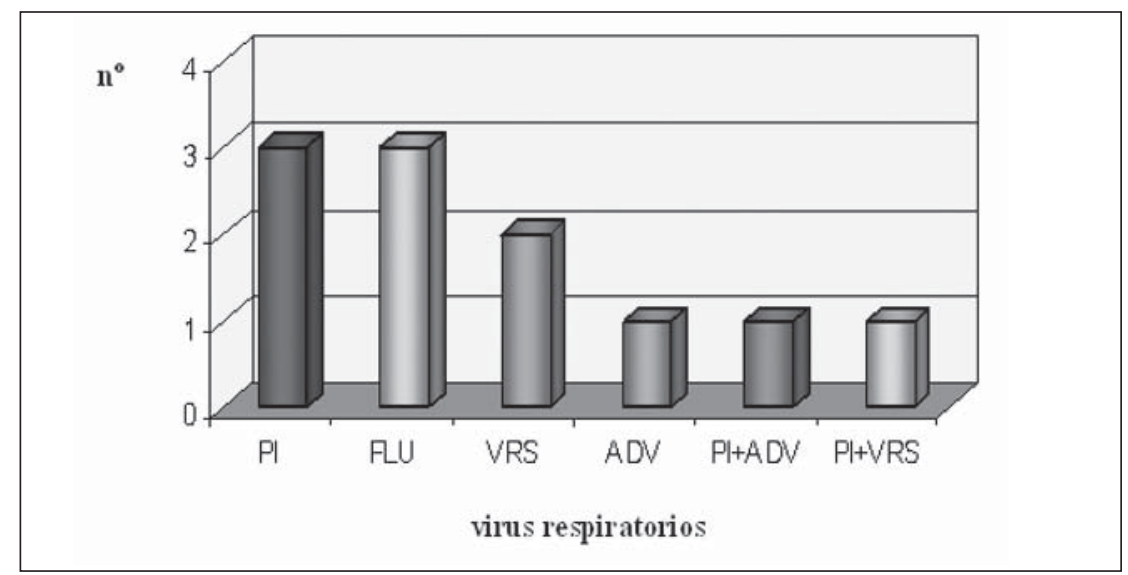

Figura 1. Distribución de frecuencia de virus respiratorios en 11 episodios de neutropenia febril correspondientes a 11 pacientes con leucemia linfoblástica aguda. PI: parainfluenza. 


\section{Tabla 1. Manifestaciones clínicas en 11 pacientes con leucemia linfoblástica aguda y neutropenia febril,} que tuvieron IFD $(+)$ para virus respiratorios

\begin{tabular}{|c|c|c|c|c|c|c|}
\hline Virus & Fecha & $\begin{array}{l}\text { Edad } \\
\text { (año, mes) }\end{array}$ & $\begin{array}{l}\text { Duración } \\
\text { de la fiebre } \\
\text { (días) }\end{array}$ & Síntomas y signos respiratorios & $\begin{array}{l}\text { Duración } \\
\text { de la tos } \\
\text { (días) }\end{array}$ & Examen pulmonar \\
\hline $\begin{array}{l}\text { Parainfluenza-1 } \\
(M p)\end{array}$ & 28/10/04 & 6,6 & 14 & Faringitis, disfonía, tos, sibilancias & 23 & $\begin{array}{l}\text { Crepitaciones en base derecha, } \\
\text { sibilancias difusas }\end{array}$ \\
\hline Parainfluenza-3 & $27 / 05 / 04$ & 4 & 3 & Coriza, faringitis, tos & 23 & $\downarrow \mathrm{MP}$ en base izquierda \\
\hline Parainfluenza-3 & $02 / 01 / 04$ & 3 & 3 & Coriza, faringitis, tos & 8 & Normal \\
\hline VRS (IIH-F) & 19/07/04 & 9 & 9 & Faringitis, tos, dificultad respiratoria & 9 & $\begin{array}{l}\text { Estertores bilaterales a broncofonía y } \\
\text { crépitos en base izquierda }\end{array}$ \\
\hline VRS (IIH) & $31 / 07 / 04$ & 13 & 4 & Faringitis, tos, disfonía, sibilancias & 9 & Estertores bilaterales, sibilancias difusas \\
\hline FLU A (IIH) & $22 / 07 / 03$ & 3,7 & 1 & Coriza, faringitis, tos, sibilancias & 22 & Estertores bilaterales, sibilancias aisladas \\
\hline FLU A & 25/07/03 & 7 & 7 & Coriza, faringitis, tos, cefalea & 5 & Estertores bilaterales \\
\hline FLU A (IIH) & $22 / 07 / 03$ & 3 & 2 & Faringitis, tos & 5 & Normal \\
\hline ADV & $11 / 11 / 04$ & 7 & 2 & $(-)$ & $(-)$ & Normal \\
\hline $\begin{array}{l}\text { ADV + } \\
\text { parainfluenza-1 }\end{array}$ & $28 / 05 / 04$ & 3 & 4 & Faringitis, tos & 6 & $\begin{array}{l}\text { Estertores bilaterales, crépitos en base } \\
\text { izquierda. }\end{array}$ \\
\hline $\begin{array}{l}\text { VRS }+ \\
\text { parainfluenza-1 }\end{array}$ & 28/05/03 & 7,11 & 7 & Coriza, faringitis, otalgia, tos, sibilancias & 7 & $\begin{array}{l}\text { Crepitaciones en base izquierda, } \\
\text { sibilancias difusas }\end{array}$ \\
\hline \multirow{2}{*}{\multicolumn{4}{|c|}{$\begin{array}{l}(\mathrm{Mp}) \text { : Coinfección con Mycoplasma pneumoniae } \\
\text { FLU: virus influenza }\end{array}$}} & VRS: virus respiratorio sincicial & \multicolumn{2}{|c|}{$(\mathrm{IIH})$ : Infección intrahospitalaria } \\
\hline & & & & (F): Desenlace fatal & ADV: adeno & MP: murmullo pulmonar \\
\hline
\end{tabular}

\begin{tabular}{|c|c|c|c|c|}
\hline Virus & $\begin{array}{l}\text { RAN de } \\
\text { ingreso } \\
\left(x \mathrm{~mm}^{3}\right)\end{array}$ & $\begin{array}{c}\text { PCR de } \\
\text { ingreso } \\
(\mathrm{mg} / \mathrm{dl})\end{array}$ & Hemocultivos & Radiografía de tórax \\
\hline Parainfluenza-1 & 600 & 20,0 & - & $\begin{array}{l}\text { Infiltrado intersticial difuso, confluente en base } \\
\text { derecha }\end{array}$ \\
\hline Parainfluenza-3 & 402 & 6,9 & - & Consolidación en base izquierda \\
\hline Parainfluenza-3 & 783 & 3,4 & - & Infiltrado intersticial bilateral \\
\hline VRS & 1.054 & 5,3 & - & $\begin{array}{l}\text { Infiltrado intersticial difuso a consolidación masiva } \\
\text { bilateral de predominio izquierdo }\end{array}$ \\
\hline VRS & 50 & 3,1 & - & Normal \\
\hline FLU A & 40 & 1,7 & - & Infiltrado intersticial bilateral \\
\hline FLU A & 988 & 2,0 & - & Infiltrado intersticial bilateral \\
\hline FLU A & 1.152 & 1,0 & - & Normal \\
\hline ADV & 504 & 14,8 & - & Normal \\
\hline ADV + parainfluenza-1 & 793 & 15,6 & - & Consolidación en base izquierda \\
\hline VRS + parainfluenza-1 & 0 & 17 & - & Infiltrado intersticial, confluente retrocardíaco \\
\hline
\end{tabular}


portador de síndrome de Down, LLA en fase de inducción de quimioterapia (QT), con infección por VRS de adquisición IIH, y agranulocitosis, que presentó brusco deterioro clínico con distress respiratorio, neumonía extensa bilateral y aumento significativo de la PCR (5,3 $\mathrm{mg} / \mathrm{dl}$ al inicio y $18 \mathrm{mg} / \mathrm{dl}$ posteriormente), evolucionando en 5 días a un cuadro séptico de origen pulmonar con shock refractario y desenlace fatal, pese a manejo en UCI, y terapia antibacteriana de amplio espectro y antifúngica; los hemocultivos fueron persistentemente negativos.

En 33 de los 44 episodios de NF (75\%) la IFD fue negativa. En 21 de éstos (64\%) los pacientes también presentaron sintomatología respiratoria, detectándose en 15 de ellos agentes atípicos: Mycoplasma pneumoniae por serología IgM en 3 y Bordetella pertussis por IFD en muestra de aspirado nasofaríngeo en 12 , por lo que recibieron tratamiento con macrólidos.

\section{Discusión}

La detección de virus respiratorios en $25 \%$ de los episodios de NF en pacientes bajo 15 años de edad, hospitalizados con diagnóstico de LLA, confirmó un porcentaje similar y sin diferencias estadísticamente significativas $(\mathrm{p}=0,85)$ con una experiencia nuestra previamente publicada ${ }^{7}$. La presencia de estos virus en la comunidad es estacional, predominando VRS y FLU en los meses fríos; VRS se presenta en otoñoinvierno con un periodo de circulación que se extiende por alrededor de 22 semanas, el virus FLU predomina en invierno y origina brotes epidémicos de 6 a 8 semanas de duración, los virus parainfluenza son prevalentes en primavera-verano (el serotipo 3) pero pueden causar brotes en otoño (los serotipos 1 y 2) y ADV circula durante todo el año. El periodo de detección viral en nuestro estudio coincide con el patrón anual de circulación epidémica de estos virus en la comunidad, al igual que lo observado en series extranjeras ${ }^{2,5,9}$.

Noventa y un por ciento de los pacientes presentó sintomatología del aparato respiratorio superior, pero con progresión al tracto respiratorio inferior en $2 / 3$ de los casos, hecho ampliamente descrito en la literatura médica $^{2,3}$. Sesenta y tres por ciento tuvo neumonía con consolidación o infiltrado intersticial confluente, característica constante en aquellos pacientes con neutropenia moderada o gravemente disminuida y PCR mayor a $6,9 \mathrm{mg} / \mathrm{dl}$, sugiriendo la presencia de una sobreinfección bacteriana y/o fúngica ${ }^{2}$.

Si bien la tos y odinofagia fueron los síntomas más constantes en todos los episodios de NF, no hubo diferencias significativas al comparar los episodios IFD (+) e IFD (-). Los pacientes con infección por virus
FLU no presentaron el clásico síndrome gripal, sus síntomas fueron inespecíficos e indistinguibles clínicamente de otras etiologías virales. No todas las infecciones por virus respiratorios se manifestaron con síntomas respiratorios, ya que al igual que en otras series $^{7}$, el paciente con infección por ADV presentó sólo fiebre y elevación de la PCR.

En el hospedero inmunocompetente las virosis respiratorias duran alrededor de 3 a 5 días y son autolimitadas; sin embargo, en inmunocomprometidos la evolución es más prolongada, en nuestro grupo se observó persistencia de fiebre y tos por 7 o más días en 40 y $70 \%$ de los casos, respectivamente.

Aquellos niños que adquirieron la infección viral durante su hospitalización tenían estadías prolongadas de 14 ó más días, situación que favoreció y explica la aparición de IIH en 1/3 de los casos. Breese ${ }^{10}$ señala que en pacientes adultos con cáncer, 50 a $75 \%$ de las virosis respiratorias son adquiridas en el hospital y los brotes se inician tras la introducción inadvertida del virus a la unidad oncológica por miembros de la familia o por personal de salud $d^{11,12}$.

En estas infecciones no se concibe el estado de colonización o portación, la detección del virus en secreciones respiratorias indica siempre infección productiva de las células del epitelio respiratorio. La excreción viral en sujetos sanos dura alrededor de 7 días, con excepción de ADV, que puede continuar eliminándose por la ruta digestiva en la convalecencia de la enfermedad y constituir una fuente de contagio para otros niños hospitalizados en la misma sala ${ }^{13}$. En cambio, en hospederos inmunocomprometidos la excreción viral suele ser más prolongada y, tanto la cuantía como la duración de ésta se correlacionan con el grado de inmunosupresión, pudiendo ser intermitente hasta por más de 100 días, aún en ausencia de sintomatología respiratoria ${ }^{3,10}$. Estas evidencias avalan la recomendación de considerar a todo paciente inmunocomprometido con infección por virus respiratorios como potencial fuente de contagio durante toda su hospitalización $^{14}$; en el paciente que falleció comprobamos la excreción persistente de VRS.

Martino $^{5}$ enfatiza que en pacientes con neoplasias hematológicas VRS compromete al tracto respiratorio inferior en la mitad de los casos, traduciéndose en una alta letalidad (80-100\%) por neumonía viral o sobreinfección bacteriana y facilitado por la falta de una terapia antiviral efectiva para su control ${ }^{3,10,15}$. Los pacientes con LLA que están recibiendo QT de inducción y altas dosis de corticosteroides constituyen una población de alto riesgo, como ocurrió en esta experiencia, donde observamos una letalidad global de $9 \%$ y letalidad asociada a VRS de $33 \%$. Hicks ${ }^{2}$ señala que uno de los factores más importantes para aminorar la 
mortalidad por virus respiratorios en pacientes inmunocomprometidos es el reconocimiento de que estas infecciones son comunes y contagiosas.

Todo paciente con NF presenta riesgo de infección bacteriana invasora (IBI). Los pacientes con IFD $(+)$ recibieron inicialmente tratamiento antimicrobiano, ya que la identificación de un agente viral no excluye la presencia de otros patógenos, especialmente bacterianos, debido a la neutropenia y a alteraciones inmunológicas secundarias tanto a la enfermedad de base como al empleo de QT y corticosteroides ${ }^{3}$. Al aplicar en nuestra serie los criterios de riesgo de IBI validados en Chile para pacientes pediátricos con cáncer ${ }^{16}$, encontramos que 8 de 11 pacientes con virus respiratorios presentaban al menos un factor de alto riesgo: 3 tenían 1, 4 tenían 2 y 1 tenía 3 . El paciente que falleció presentaba 2 factores de riesgo al ingresar al hospital, lo que apoyó una conducta terapéutica más agresiva. Los otros 3 pacientes cumplían con criterios de bajo riesgo y se trataron con esquemas antimicrobianos abreviados de primera línea ${ }^{6}$.

La detección precoz de un virus respiratorio en episodios de NF permitió aplicar medidas epidemiológicas oportunas para evitar su propagación a otros pacientes $\mathrm{y} / \mathrm{o}$ al personal de salud y administrar tratamiento antiviral específico para controlar la infección en pacientes con FLU A. Además, en episodios de bajo riesgo, permitió limitar la búsqueda de otros focos de infección, usar antibacterianos por menor tiempo y favorecer altas precoces, reduciendo el riesgo de resistencia bacteriana y los efectos adversos a medicamentos.

Recomendamos realizar estudio de virus respiratorios a todos los pacientes con cáncer y NF, especialmente en periodos epidémicos, pues sus manifestaciones clínicas pueden ser inespecíficas, clínicamente no reconocidas, confundidas con otras etiologías o estar ausentes.

La IFD es un excelente método para detectar infección por VRS en la población pediátrica (sensibilidad 95\%), es adecuado para virus FLU y parainfluenza (sensibilidad 73-83\%), pero pobre para ADV (sensibilidad 40\%). Hoy en día existen métodos de diagnóstico molecular altamente sensibles para confirmar infección viral en inmunocomprometidos ${ }^{17,18}$, que permiten una rápida detección y la posibilidad de cuantificar (carga viral) y monitorizar la infección en sangre mediante RPC, prediciendo una enfermedad grave o diseminada (de gran utilidad en infección por ADV), ensayar terapia antiviral antes de la aparición de síntomas clínicos y evaluar la respuesta terapéutica. Como ventaja adicional, ofrece la posibilidad de utilizar otro método de obtención de muestra en situaciones en que el aspirado o hisopado nasofaríngeo pueda estar contra- indicado por riesgo de hemorragias y de detectar múltiples etiologías virales en una misma muestra ${ }^{18}$.

La vacunación sólo está disponible contra virus FLU. Se recomienda hoy en día vacunar anualmente a todos los sujetos inmunocomprometidos, a sus contactos del grupo familiar y al personal de salud, indicando antivirales profilácticos y terapéuticos cuando corresponda ${ }^{14,19-21}$. En nuestro caso, ningún paciente con infección por virus FLU había recibido vacuna específica, todos se trataron con amantadina pues correspondieron a FLU A y tuvieron una evolución favorable. Los reportes de eficacia clínica de la vacuna inactivada trivalente anti-influenza en niños con cáncer han variado considerablemente desde su introducción y actualmente, varios estudios de inmunogenicidad efectuados en inmunocomprometidos permiten avalar su recomendación, en base a una adecuada respuesta humoral, buena tolerancia y reacciones adversas leves ${ }^{22-24}$.

La eficacia de la terapia antiviral en infecciones por virus FLU tratadas precozmente está ampliamente de$\operatorname{mostrada}^{21}$. En infecciones causadas por virus parainfluenza, ADV y VRS, se ha utilizado ribavirina, cidofovir, rivabirina sola o asociada a inmunoglobulina hiperinmune y anticuerpos monoclonales, respectivamente. No obstante, el uso de rivabirina es limitado debido al alto costo y al beneficio real no demostrado en la evolución clínica de los pacientes ${ }^{15,18}$.

Probablemente en un futuro no muy lejano dispongamos de una amplia gama de vacunas y nuevos antivirales, más efectivos y mejor tolerados, para prevenir y tratar infecciones por virus respiratorios en pacientes inmunocomprometidos.

\section{Agradecimientos}

Al equipo de Hemato-Oncología, tanto médicos como enfermeras, que colaboraron en el enrolamiento de pacientes y en la toma de muestra de exámenes. Al Sr. Francisco Marín H., por su contribución en la revisión y análisis estadístico.

\section{Resumen}

Los virus respiratorios constituyen una de las causas más frecuentes de infección en niños sanos. Su importancia en pacientes con cáncer sólo ha sido reconocida en los últimos años, desconociéndose la incidencia en nuestro país. Objetivo: Establecer la frecuencia y el perfil epidemiológico-clínico de las infecciones por virus respiratorios en pacientes pediátricos con leucemia linfoblástica aguda (LLA), hospitaliza- 
dos por neutropenia febril (NF). Metodología: Inmunofluorescencia directa (IFD) para virus influenza (FLU) A y B, parainfluenza 1, 2 y 3 , virus respiratorio sincicial (VRS) y adenovirus (ADV), en muestra de aspirado nasofaríngeo, a todos los pacientes bajo 15 años de edad, hospitalizados con diagnóstico de LLA y NF, entre el $1^{\circ}$ de noviembre del 2002 y el 31 de octubre del 2004, en el Hospital Clínico Regional de Valdivia (HCRV). Resultados: Se detectó virus respiratorios en $25 \%$ de 44 episodios de NF, correspondientes a 25 pacientes: FLU (3/11), parainfluenza (3/11), VRS (2/11),
ADV (1/11), parainfluenza + VRS (1/11), parainfluenza + ADV (1/11). Hubo adquisición intrahospitalaria en $36 \%$. Síntomas respiratorios presentaban $91 \%$ de los pacientes y compromiso del tracto respiratorio inferior en $73 \%$. Un paciente falleció debido a infección persistente por VRS, agranulocitosis y neumonía extensa bilateral. Conclusiones: Las infecciones por virus respiratorios son frecuentes y potencialmente graves en niños con cáncer, por lo que las pruebas de diagnóstico viral deben incluirse en el estudio de NF durante la temporada de otoño e invierno.

\section{Referencias}

1.- Pizzo P. Fever in immunocompromised patients. N Engl J Med 1999; 341: 893-900.

2.- Hicks K, Chemaly R, Kontoyiannis D. Common community respiratory viruses in patients with cancer. Cancer 2003; 97: 2576-87.

3.- Ravella N, Rodríguez P, Labeaga R, Otegui M, Mercader M, Gurguí M, et al. Conventional respiratory viruses recovered from immunocompromised patients: Clinical considerations. Clin Infect Dis 1999; 28: 1043-8.

4.- Arola M. Respiratory virus infections during anticancer treatment in children. Pediatr Infect Dis J 1995; 14: 690-4.

5.- Martino R, Rámila E, Rabella N, Muñoz J M, Peyret M, Portos JM, et al. Respiratory virus infections in adults with hematologic malignancies: A prospective study. Clin Infect Dis 2003; 36:1-8.

6.- Hormaechea A, Martínez P, Zolezzi P, Folatre I, Cruz C, Leal N, et al. Neutropenia febril en menores con leucemia linfoblástica aguda. Rev Chil Pediatr 2004; 75: 146-52.

7.- Täger M, Zolezzi P, Navarrete M, Rojas J, Folatre I. Detección de virus respiratorios mediante técnica de inmunofluorescencia directa en niños con leucemia linfoblástica aguda y neutropenia febril. Rev Chil Pediatr 2004; 75: 139-45.

8.- Mathey S, Nicholson D, Ruhs S. Rapid detection of respiratory virus by shell vial culture and direct staining by using pooled and individual monoclonal antibodies. J Clin Microbiol 1992; 30: 540-4.
9.- Englund J. Diagnosis an epidemiology of community-acquired respiratory virus infections in the immunocompromised host. Biol Blood Marrow Transplant 2001; 7 Suppl: 2S-4S.

10.- Breesse C. Nosocomial respiratory syncytial virus infections: The cold war has not ended. Clin Infect Dis 2000; 31: 590-6.

11.- Yousuf H, Englund J, Couch R, Rolston K, Luna M, Goodrich J, et al. Influenza among hospitalized adults with leukemia. Clin Infect Dis 1997; 24: 1095-9.

12.- Buxton C, Kuehnert M, Hall C. Transmission of influenza: implications for control in health care settings. Clin Infect Dis 2003; 37: 1094-01.

13.- Pickering L K, ed. 2000 Red Book: Report of the Committee on Infectious Diseases. 25th ed. Ek Grove Village, IL: American Academy of Pediatrics 2000: 162-3.

14.- Ferrés M. Vacunación anti-influenza en inmunocomprometidos. Documento Sociedad Chilena de Infectología. Abril 2003. (http://www. sochinf.cl). Accedido 24 julio 2005 .

15.- Breesse C. Respiratory syncitial virus and parainfluenza virus. N Engl J Med 2001; 344: 1917-28.

16.- Santolaya M E, Álvarez A, Avilés C, Becker A, Cofré J, Payá E, et al. Tratamiento selectivo de los episodios de neutropenia febril en niños con cáncer. Comité de Infectología, Programa Nacional de Drogas Antineoplásicas. Rev Chil Infect 2004; 21: 213-22.

17.- Watzinger F, Suda M, Preuner S, Baumgartinger R, Ebner K, Baskova L, et al.
Real -time quantitative PCR assays for detection and monitoring of pathogenic human viruses in immunosupressed pediatric patients. J Clin Microbiol 2004; 42: 5189 98.

18.- Pehler-Harrington K, Khanna M, Waters C, Henrickson K. Rapid detection and identification of human adenovirus species by Adenoplex, a multiplex PCR-enzyme hybridization assay. J Clin Microbiol 2004; 42: 4072-6.

19.- CDC Influenza chemoprophylaxis and treatment. Guidelines 2005-2006. www.cdc.gov./flu/professionals/treatment/ pda (Accedido 6 abril 2006).

20.- Jofré J, Perret C, Dabanch J, Abarca K, Olivares R, Luchsinger V. Influenza: reemergencia de una antigua enfermedad y el potencial riesgo de una nueva pandemia. Rev Chil Infect 2005; 22: 75-88.

21.- Couch R. Prevention and treatment of influenza. N Engl J Med 2000; 343: 1778-87.

22.- Chisholm JC, Devine T, Charlett A, Pinkerton CR, Zambon M. Response to influenza immunization during treatment for cancer. Arch Dis Child 2001; 84: 496-5000

23.- Porter CC, Edwards KM, Zhu Y, Frangoul H. Immune responses to influenza in children receiving maintenance chemotherapy for acute lymphoblastic leukemia. Pediatr Blood Cancer 2004; 42: 36-40

24.- Brydak LB, Rokicka-Milewska R, Machala M, Jackowska T, Sikorska-Fic B. Immunogenicity of subunit trivalent influenza vaccine in children with acute lymphoblastic leukemia. Pediatr Infect Dis J 1998; 17: 125-9. 